\title{
Validation of the verbal autopsy questionnaire for adult deaths in Iran
}

\author{
Azizallah Dehghan ${ }^{1,2}$, Maryam Nasirian ${ }^{3,1}$, Ali Akbar Haghdoost ${ }^{4}$, Ehsan Bahramali ${ }^{5}$, Hamid Sharifi*1,6 \\ Received: 13 Jan 2017 \\ Published: 7 Feb 2018
}

\begin{abstract}
Background: Verbal Autopsy Questionnaire (VA) is an important tool to estimate the cause of death among those populations lacking an appropriate death registration system. In this study, the validity and reliability of verbal autopsy were assessed.

Methods: The Persian version of the questionnaire was prepared using the translation and back- translation method. In the first and second phases of the study, 213 and 198 families of deceased persons accepted an invitation to complete the questionnaire. A physician determined the cause of death. These causes were compared with the registered cause of death on the death certificate. Sensitivity, specificity, positive predictive value (PPV), as well as the kappa statistic (between the first verbal autopsy questioning and death registry) were calculated to determine the validity of the questionnaire. Kappa statistic was also used to determine the reliability between the first and second questioning.

Results: The sensitivity of the questionnaire varied from $75 \%$ among deaths due to diabetes to $100 \%$ Due to breast cancer. The specificity of the questionnaire for all causes of death was higher than $97 \%$. PPV varied from $62.5 \%$ to $100 \%$ for all causes of death. The kappa statistic between causes of death derived from death certificate, and the first VA questioning for all causes of death was above 0.7 ( $\mathrm{p}<0.001)$, and it was above 0.78 for the first and second verbal autopsy questioning $(\mathrm{p}<0.001)$.

Conclusion: Although the Verbal Autopsy Questionnaire does not fully identify all causes of death, it can be a useful tool for diagnosing causes of death for those deceased persons who have no death certificate.
\end{abstract}

Keywords: Validation, Reliability, Verbal autopsy, Mortality

Copyright $₫$ Iran University of Medical Sciences

Cite this article as: Dehghan A, Nasirian M, Haghdoost AA, Bahramali E, Sharifi H. Validation of the verbal autopsy questionnaire for adult deaths in Iran. Med J Islam Repub Iran. 2018(7 Feb);32:7. https://doi.org/10.14196/mjiri.32.7

\section{Introduction}

Information on causes of death is essential for policymakers, planners, and managers to plan, implement, monitor, and evaluate public health at every level (local and district, provincial, national and international levels) (1).

Inadequate reliable information on mortality rate and cause of poor inhabitants in the world causes limitation of all efforts to establish strong evidences for health policymaking, planning, monitoring, and evaluating. In those regions where the majority of deaths happen at home and there is a lack of vital incidences registry systems, there is little chance to document deaths that occur far from health

\section{Corresponding author: Dr Hamid Sharifi, sharifihami@gmail.com}

1. HIV/STI Surveillance Research Center, and WHO Collaborating Center for HIV Surveillance, Institute for Futures Studies in Health, Kerman University of Medical Sciences, Kerman, Iran.

2. Social Medicine Department, School of Medicine, Fasa University of Medical sciences, Fasa, Iran.

3. Epidemiology and Biostatistics Department, Health School; and Infectious Diseases and Tropical Medicine Research Center, Isfahan University of Medical Sciences, Isfahan, Iran

4. Modeling in Health Research Center, Institute for Futures Studies in Health, Kerman University of Medical sciences, Kerman, Iran.

5. Noncommunicable Diseases Research Center, Fasa University of Medical Sciences, Fasa, Iran.

6. Department of Biostatistics and Epidemiology, School of Public Health, Kerman University of Medical Sciences, Kerman, Iran. centers, let alone registering their causes (2). Many countries with the highest burden of disease lack a routine and high-quality information on causes of death (3). Therefore, there is a vital need for a tool to determine the cause of death. Verbal Autopsy (VA) Questionnaire is a suitable tool to determine death causes in those regions with or without poor registry system (4).

Verbal autopsy is a method to determine the cause of death and for this purpose, care takers, friends, or family members are asked for signs and symptoms of the patient prior to death. Further autopsy interviews will be conducted using standard questionnaires to gather details of signs and

$\uparrow$ What is "already known" in this topic:

The accurate record of the cause of death can be important for policy- makers. Many deaths occur with unknown causes, and Verbal Autopsy Tool can help determine those causes of death that are unclear. In this study, the validity and reliability of the Verbal Autopsy tool was examined.

$\rightarrow$ What this article adds:

This study showed that Verbal Autopsy Tool has an almost good validity and reliability to detect causes of adult deaths. 
symptoms, complaints, and any previous medical history and events. The cause of death or the sequences of death causes are determined based on gathered information through this questionnaire and any available information. To avoid recall bias among respondents, it is recommended to assess registered deaths in the past years, choose respondents who were near the deceased person at the time of death, and avoid asking those who were not beside the deceased person prior to death (5). This questionnaire is being used in various countries, especially in less developed countries (2, 6-8). It has also been used in a cohort study in Golestan, Iran, and the results were acceptable; however, further studies are recommended (9).

Each tool entered into a new language and culture should have suitable validity and reliability $(10,11)$. Validity and reliability of each tool indicate its accuracy and precision. The low error rate increases confidence in the tool (12).

In Iran, death registration system was started as a pilot project in 1998 in Bushehr, Iran, and it is being implemented regularly in all provinces of Iran (31 provinces) since 2004. Completing death certificate and death registry is being implemented in hospitals, health centers, cemeteries, and forensics of each city (13); however, similar to all other countries, under numeration, misclassification, and incorrect registry are 3 problems in death registry in Iran (14). Also, to collect accurate information on the causes of death in all countries and for comparability of countries, The WHO has recommended the same death certificates and verbal autopsy tools (15). Thus, verbal autopsy is required to be recorded more accurately. Considering the need for VA tool in Iran, this study was conducted to translate this tool and evaluate its validity and reliability in Iran.

\section{Methods}

In this 2-stage cross-sectional survey, the English version of the Verbal Autopsy Questionnaire was translated into Persian (16) by an epidemiologist and a linguist. The Persian translation was back-retranslated into English by a different team including a physician and a linguist; then, the Persian version of Verbal Autopsy Questionnaire was prepared.

Those who have died in the last year (1239 deaths) were selected by simple random sampling from the archive of Lorestan Health Centre, Fars province, Iran. Inclusion criteria for the study were as follow: age older than 15 years at the time of death, deaths occurring within the past year, and the cause of death had to be accurately recorded in the hospital. Two nurses were selected as interviewers and were trained for questioning skills. They visited the homes of the deceased persons after obtaining oral consent from the family members and explaining the aim of the study. After questioning, the cause of death was determined by a trained physician using the completed questionnaires.

\section{Sample size}

According to the theory of Fire et al., 100 to 400 people are needed to assess the validity of the questionnaire (17). In the current study, 250 adult cases (over 15 years old at time of death) were selected for the VA Questionnaire by random sampling from 1012 recorded deaths in the health centre in 2013. After explaining the aim and the method of the study, 213 family members agreed to cooperate. In the second stage of the study, 198 family members agreed to cooperate. The purpose of the first phase of the study was to determine the validity of the questionnaire, and in the second phase of study, the reliability of the questionnaire was assessed. The second phase was performed 2 weeks after the first phase. Before starting the study, informed consent was obtained from all participants, and they were assured of the confidentiality of their personal information.

\section{Validity and reliability assessment}

Sensitivity, specificity, and positive predictive value were used to determine the construct validity, and kappa index was used to assess the criterion validity of the questionnaire. The gold standard diagnosis of the cause of death for assessing the validity of the VA was the cause of death recorded in hospital medical records.

The ability of the questionnaire to correctly diagnose the cause of death due to a particular cause is called sensitivity. In the current study, specificity is defined as the ability to correctly diagnose that someone has not died of a specific cause. Positive predictive value is defined as the correctness probability of the determined cause of death for a person (14). The agreement between the registered death cause and the death cause obtained from the first stage of the VA Questionnaire was used to measure validity, and agreement between the first and second stages of VA Questionnaire was used to measure reliability.

\section{Statistical analyses}

Sensitivity, specificity, positive predictive value, accuracy index, and kappa index were computed with Microsoft Office Excel 2007. A 95\% binomial proportion confidence interval was calculated for all indicators (sensitivity, specificity, and positive predictive value) by an exact method in Stata 11 software.

\section{Results}

The study was conducted on 213 deaths, 134 (62.9\%) males and $79(37.1 \%)$ females. The time for interview and competing the questionnaire was $32 \pm 11$ minute. The greatest sensitivity was in the diagnosis of breast cancer (100\%) and the lowest was in the diagnosis of diabetes (75\%). Table 1 demonstrates the values of sensitivity, specificity, and positive predictive value of each cause of death.

From 213 deaths in the first phase of the study, 198 (92.9\%) cases participated in the second VA phase. The cause of death in the first and second phases and kappa index are presented in Table 2. The $183(92.42 \%)$ deaths in both phases had the same cause of death. Kappa index for each cause of death is presented in Table 2.

\section{Discussion}

In this study, causes of $85 \%$ of deaths were correctly diagnosed using VA Questionnaire, which can almost be considered a good estimation. In a study by Yang et al., in China, $96 \%$ of deaths were detected by VA questionnaires (2). Khademi et al., in Golestan, Iran, stated that nearly $80 \%$ of deaths, compared with the gold standard, were truly 
A. Dehghan, et al.

\begin{tabular}{|c|c|c|c|c|c|c|c|c|}
\hline Cause of death & $\begin{array}{l}\text { Death certifi- } \\
\text { cate }\end{array}$ & $\mathrm{VA}^{*}$ & $\begin{array}{c}\text { Death certificate } \\
\& \mathrm{VA}^{*}\end{array}$ & $\begin{array}{c}\text { Sensitivity } \\
(95 \% \mathrm{CI})\end{array}$ & $\begin{array}{l}\text { Specificity } \\
(95 \% \text { CI })\end{array}$ & $\begin{array}{c}\text { PPV }^{* *} \\
(95 \% \mathrm{CI})\end{array}$ & Accuracy & Kappa \\
\hline Brest cancer & 6 & 7 & 6 & 100 & $\begin{array}{c}99.5 \\
(97.33-99.9)\end{array}$ & $\begin{array}{c}85.7 \\
(42.1-99.6)\end{array}$ & 99.53 & 0.79 \\
\hline $\begin{array}{l}\text { Cerebrovascular } \\
\text { disorders }\end{array}$ & 25 & 28 & 23 & $\begin{array}{c}92.0 \\
(73.9-99.0)\end{array}$ & $\begin{array}{c}97.3 \\
(93.9-99.1)\end{array}$ & $\begin{array}{c}82.1 \\
(63.1-93.9)\end{array}$ & 97.65 & 0.84 \\
\hline $\begin{array}{l}\text { Transport } \\
\text { accident }\end{array}$ & 10 & 11 & 9 & $\begin{array}{c}90.0 \\
(55.4-99.7)\end{array}$ & $\begin{array}{c}99.0 \\
(96.4-99.8)\end{array}$ & $\begin{array}{c}81.8 \\
(48.2-97.7)\end{array}$ & 98.59 & 0.84 \\
\hline Colorectal cancer & 7 & 8 & 6 & $\begin{array}{c}85.7 \\
(42.1-99.6)\end{array}$ & $\begin{array}{c}99.0 \\
(96.5-99.8)\end{array}$ & $\begin{array}{c}75.0 \\
(34.9-96.8)\end{array}$ & 98.59 & 0.79 \\
\hline Lung cancer & 7 & 9 & 6 & $\begin{array}{c}85.7 \\
(42.1-99.6)\end{array}$ & $\begin{array}{c}98.5 \\
(95.8-99.6)\end{array}$ & $\begin{array}{c}66.6 \\
(29.9-92.5)\end{array}$ & 98.12 & 0.74 \\
\hline Other cancers & 12 & 12 & 10 & $\begin{array}{c}83.3 \\
(51.5-97.9)\end{array}$ & $\begin{array}{c}99.0 \\
(96.4-99.8)\end{array}$ & $\begin{array}{c}83.3 \\
(51.5-97.9)\end{array}$ & 98.12 & 0.82 \\
\hline Stomach cancer & 6 & 8 & 5 & $\begin{array}{c}83.3 \\
(35.8-99.5)\end{array}$ & $\begin{array}{c}98.5 \\
(95.8-99.7)\end{array}$ & $\begin{array}{c}62.5 \\
(24.4-91.4)\end{array}$ & 98.12 & 0.70 \\
\hline $\begin{array}{l}\text { Respiratory } \\
\text { disease }\end{array}$ & 16 & 13 & 13 & $\begin{array}{c}81.2 \\
(54.3-95.9)\end{array}$ & 100 & 100 & 98.59 & 0.88 \\
\hline Other causes & 22 & 19 & 18 & $\begin{array}{c}81.8 \\
(59.7-94.8)\end{array}$ & $\begin{array}{c}98.4 \\
(95.4-99.6)\end{array}$ & $\begin{array}{c}94.7 \\
(73.9-99.8)\end{array}$ & 97.65 & 0.86 \\
\hline $\begin{array}{l}\text { Ischemic heart } \\
\text { disease }\end{array}$ & 32 & 29 & 28 & $\begin{array}{c}87.5 \\
(71.0-96.4)\end{array}$ & $\begin{array}{c}99.4 \\
(96.9-99.9)\end{array}$ & $\begin{array}{c}96.5 \\
(82.2-99.9)\end{array}$ & 97.65 & 0.90 \\
\hline Liver disease & 16 & 14 & 14 & $\begin{array}{c}87.5 \\
(61.6-98.4)\end{array}$ & 100 & 100 & 99.06 & 0.92 \\
\hline COPD & 16 & 18 & 14 & $\begin{array}{c}87.5 \\
(61.698 .4)\end{array}$ & $\begin{array}{c}97.9 \\
(94.8-99.4)\end{array}$ & $\begin{array}{c}77.7 \\
(52.3-93.5)\end{array}$ & 97.18 & 0.80 \\
\hline Infectious disease & 13 & 10 & 10 & $\begin{array}{c}76.9 \\
(46.1-94.9)\end{array}$ & 100 & 100 & 98.59 & 0.86 \\
\hline Kidney disease & 13 & 14 & 10 & $\begin{array}{c}76.9 \\
(46.1-94.9)\end{array}$ & $\begin{array}{c}98.0 \\
(94.9-99.4)\end{array}$ & $\begin{array}{c}71.4 \\
(41.8-91.6)\end{array}$ & 96.71 & 0.72 \\
\hline Diabetes & 12 & 13 & 9 & $\begin{array}{c}75.0 \\
(42.8-94.5)\end{array}$ & $\begin{array}{c}98.0 \\
(94.9-99.4)\end{array}$ & $\begin{array}{c}69.2 \\
(38.5-90.9)\end{array}$ & 96.71 & 0.70 \\
\hline Total & 213 & 213 & 181 & & & & & \\
\hline
\end{tabular}

$\mathrm{VA}^{*}:$ verbal autopsy

$\mathrm{PPV}^{* *}$ : positive predictive value

Table 2. Kappa statistic between first and second verbal autopsy questioning to measure reliability

\begin{tabular}{|c|c|c|c|c|c|}
\hline Cause of death & $\mathrm{VA}^{*} 1$ & $\mathrm{VA}^{*} 2$ & $\mathrm{VA}^{*} 1 \& \mathrm{VA}^{*} 2$ & Kappa statistic & P-Value \\
\hline Brest cancer & 7 & 7 & 7 & 1 & $<0.001$ \\
\hline Ischemic heart disease & 20 & 21 & 20 & 0.97 & $<0.001$ \\
\hline Liver disease & 13 & 14 & 13 & 0.96 & $<0.001$ \\
\hline Transport accident & 11 & 12 & 11 & 0.95 & $<0.001$ \\
\hline Stomach cancer & 8 & 7 & 7 & 0.93 & $<0.001$ \\
\hline Colorectal cancer & 8 & 9 & 8 & 0.93 & $<0.001$ \\
\hline Cerebrovascular disease & 25 & 26 & 24 & 0.93 & $<0.001$ \\
\hline Respiratory disease & 13 & 15 & 13 & 0.92 & $<0.001$ \\
\hline Kidney disease & 14 & 14 & 13 & 0.92 & $<0.001$ \\
\hline COPD & 16 & 14 & 14 & 0.92 & $<0.001$ \\
\hline Other causes & 19 & 18 & 17 & 0.91 & $<0.001$ \\
\hline Total cancer & 44 & 41 & 39 & 0.89 & $<0.001$ \\
\hline Lung cancer & 9 & 7 & 7 & 0.87 & $<0.001$ \\
\hline Other cancers & 12 & 11 & 10 & 0.86 & $<0.001$ \\
\hline Infectious disease & 10 & 11 & 9 & 0.84 & $<0.001$ \\
\hline Diabetes & 13 & 12 & 10 & 0.78 & $<0.001$ \\
\hline Total & 198 & 198 & 183 & & \\
\hline
\end{tabular}

VA*: verbal autopsy

identified, which was almost similar to our study (9). Incompleteness in determining the cause of death could be due to the similarity of some symptoms of fatal diseases, which may cause misclassification.

Sensitivity for different causes of death varied and ranged from $75 \%$ to $100 \%$. Diagnosis of breast cancer had the most sensitivity; in other words, all cases of death from breast cancer were detected using verbal autopsy, and this could be due to the specificity of the symptoms of breast cancer. The lowest sensitivity was related to diagnosis of diabetes. In other studies in other regions of the world, the sensitivity and specificity for different causes of death varied and had no similar pattern, and in each study, one or more causes of death showed higher sensitivity $(2,6-8)$.

Specificity is another indicator used in the assessment of diagnostic tests, which was calculated in this study. Specificity for all causes of death was higher than 97.3, which is very good. In other studies, the level of specificity has been acceptable and all reports have been higher than $90 \%(2,7$, 9). Because many deaths occurred with no particular cause, the amount of specificity was high.

Another important indicator calculated was positive predictive value; the maximum PPV was related to infectious and respiratory diseases $(100 \%)$, and the lowest rate was associated with gastric cancer $(62.5 \%)$. Kappa statistics among the causes listed on the death certificate and causes 
diagnosed by VA varied from 0.70 for diabetes and gastric cancer to 0.88 for respiratory diseases, which was appropriate and showed high agreement among the causes listed on the death certificate and VA. Also, kappa statistics between the first and second stages of VA to assess the reliability of the VA method revealed a very good agreement. Kappa statistics for all causes of death was higher than 0.84 . In general, kappa statistic between 0.61 and 0.80 indicates considerable agreement and higher than 0.81 shows ideal agreement (18). In a systematic review on 19 studies around the world, the parameters of sensitivity and specificity for various causes of death varied in different study (6).

The skills of the interviewers and physicians can also lead to increased sensitivity and other indicators. Also, another most important limitation of this study and probably that of other studies is that the causes of death recorded in the death certificates in hospitals are considered as the gold standard, which may cause some problems. One is doubts about the authenticity of the recorded causes of death, and the other is that deaths recorded in hospitals are not representative of all deaths that occur in the society. Moreover, in this study, the sample size was small, which was due to such problems as limited financial resources. Lack of cooperation was another problem in this study. These limitations might have reduced the accuracy of the results.

\section{Conclusion}

The results of this study indicated that VA Questionnaire may not be an appropriate tool to identify some of the causes of death. However, it can be used in areas where there is no precise death registration system, or in areas where despite having a death registration system, death causes are not clear. VA Questionnaire can also be used for deaths that occur in places other than hospitals.

\section{Acknowledgements}

We would like to acknowledge the research deputy of Kerman University of Medical Sciences and HIV/STI Surveillance Research Center, and WHO Collaborating Center for HIV Surveillance, Institute for Futures Study in Health, Kerman University of Medical Sciences for funding this study and all respondents to the questionnaire.

\section{Funding/support}

Research deputy of Kerman University of Medical Sciences and HIV/STI Surveillance Research Center, and WHO Collaborating Center for HIV Surveillance, Institute for Futures Study in Health, Kerman University of Medical Sciences, Kerman, Iran

\section{Conflict of Interests}

The authors declare that they have no competing interests.

\section{References}

1. Abouzar G. Verbal autopsy: who needs it? Population Health Metrics. $2011 ; 9$.

2. Yang G, Rao C, Ma J, Wang L, Wan X, Dubrovsky G, et al. Validation of verbal autopsy procedures for adult deaths in China. Int J Epidemiol. 2005;35(3):741-8.

3. Mathers CD, Ma Fat D, Inoue M, Rao C, Lopez AD. Counting the dead and what they died from: an assessment of the global status of cause of death data. Bull World Health Organ. 2005;83(3):171-7.

4. Chandramohan D, Maude GH, Rodrigues LC, Hayes RJ. Verbal autopsies for adult deaths: issues in their development and validation. Int J Epidemiol. 1994;23(2):213-22.

5. Zahr CA. Verbal autopsy standards: ascertaining and attributing cause of death. World Health Organ; 2007.

6. Leitao J, Desai N, Aleksandrowicz L, Byass P, Miasnikof P, Tollman $\mathrm{S}$, et al. Comparison of physician-certified verbal autopsy with computer-coded verbal autopsy for cause of death assignment in hospitalized patients in low-and middle-income countries: systematic review. BMC Med. 2014;12(1):22.

7. Setel PW, Whiting DR, Hemed Y, Chandramohan D, Wolfson LJ, Alberti K, et al. Validity of verbal autopsy procedures for determining cause of death in Tanzania. Trop Med Int Health. 2006;11(5):681-96.

8. Tadesse S. Validating the InterVA model to estimate the burden of mortality from verbal autopsy data: a population-based cross-sectional study. PLoS ONE. 2013;8(9):e73463.

9. Khademi H, Etemadi A, Kamangar F, Nouraie M, Shakeri R, Abaie B, et al. Verbal autopsy: reliability and validity estimates for causes of death in the Golestan Cohort Study in Iran. PLoS ONE. 2010;5(6):e11183.

10. Dehghan A, Ghaem H, Borhani-Haghighi A, Safari-Faramani R, Moosazadeh M, Gholami A. Evaluation of reliability and validity of PDQ-39: questionnaire in iranian patients with Parkinson's disease. Zahedan J Res Med Sci. 2016;18(3).

11. Ghaem H, Zeghami B, Dehghan A. Validity and reliability of the Persian version of the Parkinson disease quality of life (PDQL) questionnaire. J Kerman univ Med Sci 2010;16(1):49-57.

12. Kimberlin CL, Winetrstein AG. Validity and reliability of measurement instruments used in research. Am J Health Syst Pharm. 2008;65(23).

13. Jafari N, Kabir MJ, Motlagh ME. Death registration system in IR Iran. Iran J publ Health. 2009;38(Suppl 1):127-9.

14. Khosravi A, Taylor R, Naghavi M, Lopez AD. Mortality in the islamic republic of Iran, 1964-2004. Bull World Health Organ. 2007;85(8):607-14.

15. Soleman N, Chandramohan D, Shibuya K. Verbal autopsy: current practices and challenges. Bull World Health Organ. 2006;84(3):23945.

16. Gorecki C, Brown JM, Briggs M, Coleman S, Dealey C, McGinnis $\mathrm{E}$, et al. Language translation \& cross-cultural adaptation guideline. 2014.

17. Fayers PM, Machin D. Quality of life: the assessment, analysis and interpretation of patient-reported outcomes. John Wiley \& Sons; 2013. 18. Sim J, Wright CC. The kappa statistic in reliability studies: use, interpretation, and sample size requirements. Phys Ther. 2005;85(3):25768. 